Volume 10, No.2, March - April 2021

International Journal of Advanced Trends in Computer Science and Engineering

Available Online at http://www.warse.org/IJATCSE/static/pdf/file/ijatcse1061022021.pdf

https://doi.org/10.30534/ijatcse/2021/1061022021

\title{
Energy Management System for Integration of Different Renewable Energy System into Microgrids
}

\author{
Muhammad Tamoor ${ }^{1 *}$, Muhammad Abu Bakar Tahir ${ }^{2}$, Muhammad Ans Zaka ${ }^{3}$ \\ ${ }^{* 1} \mathrm{PhD}$ Scholar, Department of Electrical Engineering, GC University Faisalabad, Pakistan \\ ${ }^{2}$ MS Scholar, Automotive Engineering for Sustainable Mobility, University of Orleans, France \\ ${ }^{3}$ Energy and Environmental Engineer, Zeecon Engineering Services, Pakistan \\ *Corresponding Author Email Address: phd.20.muhammadtamoor@ gmail.com
} Oric ID: 0000-0003-0981-9904

\begin{abstract}
Renewable energy (RE) is currently being used on a wide scale to meet the rising demand for energy, minimise pollution in environmental, and achieve sustainable social and economic benefits. This paper focuses on the design and development of EMS that can ensure the safe operation of island microgrids (MGs) in the event of possible imbalances between load demand and power generation. Energy management system (EMS) performs optimized calculations for the low priority loads that need to be shut down and the charging and discharging cycle of the batteries in the microgrid (MG). The non-linear model predictive control (NMPC) algorithm was selected to implement energy management system, which processes a data set consisting of power generation, load measurement, battery state of charge (SOC), and set of operating constraints. Energy management system was designed under assumption of installing Advanced Metering Infrastructure (AMI) in MG. Energy management system (EMS) was tested on a simulation platform that integrates a model of the microgrid (MG) component and its distributed controller (DC). The simulation results demonstrate the effectiveness of this method, because even when there is a fault in one of the distributed controllers, key variables such as the voltage and frequency amplitude of the microgrid (MG) will operate within a secured interval.
\end{abstract}

Key words: Energy management system, Microgrid, Renewable energy resources, Photovoltaic array, Wind turbine generator, Diesel engine, Energy storage system

\section{INTRODUCTION}

The main reason for the rapid depletion of fossil fuels and the increase in greenhouse gas (GHG) emissions from conventional generators is the exponential increase in global energy demand. In past ten years, the world has taken actions to deploy (RERs) renewable energy resources on a wide scale to overcome these issues [1], [2]. Renewable energy resources like biomass energy, wind energy, solar energy, hydropower and tidal energy, etc. are one of the most important energy sources to provide clean energy for sustainable development and reducing greenhouse gas emissions (GHG) [3]. Goals of the Paris Agreement on Climate Change (December 2015) and United Nations (UN) Sustainable Development also promote the installation of renewable energy resources. In 2016, due to increased awareness of climate change, the global deployment of renewable energy resource (RER) excluding hydropower reached 0.921 TW (921.0 GW). People's Republic of China was the first to deploy renewable energy resources, followed by the United States of America and Germany shown in Figure 1.

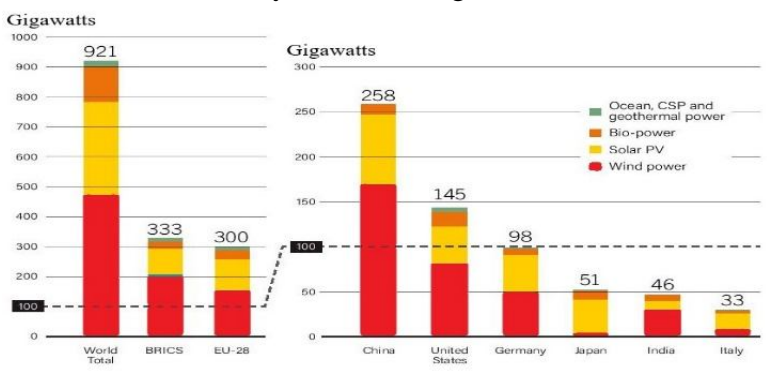

Figure 1: Global Deployment of Renewable Energy Resources (RERs)

Renewable energy resources, energy storage system (ESS) and micro conventional generator (CG) is often described as DERs (distributed energy resources) [4]. Distributed energy resources are onsite energy production resources in the distribution system. Therefore, to transfer power to the load side no transmission system or equipment is required. In distributed energy resources, Renewable energy resource (especially solar energy and wind energy) is a volatile and intermittent energy source. Therefore, energy storage system (ESS) and micro conventional generator (CG) is required to overcome these uncertainties. Integrating distributed energy resource (DER) into the distribution network require optimum sizing, monitoring, control and scheduling of these energy sources. Microgrid reflects these problems by integrating distributed energy resource in-to the grid and the abilities to operate in island modes during faults or power outages in the main grid [5]. Therefore, it helps to achieve the following goals: effective conversion of passive networks to active networks, reliable and continuous power supply, bidirectional and controllable power flow management, improved power quality characteristics and a clean environment.

Microgrid is defined or describe as a low voltage power distribution network interconnecting distributed energy resources, critical loads and controllable loads. According to the operating characteristics of the main grid, it could be operate in grid connected or island mode [6], [7]. In order to make flexible microgrid (MG) operation, Power Electronic Interface (PEI) and control are integrated with distributed energy resources (DER) to monitor power 
quality, reliable and uninterrupted/continuous power supply [8].

Microgrid has the following advantages: reduce emissions of greenhouse gas, reactive power support for improvement in voltage profile, decentralized power supply, integration of heat load for cogeneration, demand response and auxiliary services [8]. It also decrease power outages and line losses in the distribution and transmission system. Table 1 shows global deployment market of microgrid (MG). Autonomous microgrid (MG) is defined as a microgrid that could not meet the loads demand 24:00 hours a day. However, the autonomous microgrid (MG) has provision that it must supply power to the load side all day. Autonomous microgrids have been deployed around the world outside the Middle East, while autonomous, complete and integrated community based microgrids are still in the developing and pilot stages of deployment [9].

Table 1: MicrogridMarket Status

\begin{tabular}{|c|c|c|c|}
\hline Regions & $\begin{array}{c}\text { Autonomous } \\
\text { Full }\end{array}$ & $\begin{array}{c}\text { Autonomous } \\
\text { Basic }\end{array}$ & $\begin{array}{c}\text { Interconnected } \\
\text { Community }\end{array}$ \\
\hline $\begin{array}{c}\text { Middle } \\
\text { East }\end{array}$ & Pilots & Limited & Limited \\
\hline $\begin{array}{c}\text { East and } \\
\text { South } \\
\text { Asia }\end{array}$ & $\begin{array}{c}\text { Pilots/Emerg } \\
\text { ing/Mature }\end{array}$ & Mature & Emerging \\
\hline $\begin{array}{c}\text { Central } \\
\text { and } \\
\text { North } \\
\text { Asia }\end{array}$ & Limited & $\begin{array}{c}\text { Pilots/Emerg } \\
\text { ing }\end{array}$ & Limited \\
\hline $\begin{array}{c}\text { North } \\
\text { America }\end{array}$ & Emerging & Mature & Limited \\
\hline $\begin{array}{c}\text { South } \\
\text { America }\end{array}$ & Emerging & Mature & Limited \\
\hline $\begin{array}{c}\text { Central } \\
\text { America }\end{array}$ & Emerging & Mature & Emerging \\
\hline Oceania & Emerging/M & Mature & Pilots \\
\hline
\end{tabular}

Microgrid has some limitations, like the high investment cost of renewable energy resource (RER), optimal use of energy, deficiency in system protection, control issues, regulatory standards and privacy of customers. Due to the inherently high deployment of intermittent renewable energy resources and the increasing integration of probabilistic controlled load into microgrid, we have focused on solving problems faced in energy management.

EMS of microgrid not only meets the system constraints, but also covers the management of both the supply and demand sides to realize the cost-effective, stable and reliable microgrid operation [10]. Energy management system offers several benefits from power generation scheduling to power saving, reactive power support for frequency regulation, energy balance for reduction of greenhouse gas emissions emissions (GHG) and customer contribution in customer privacy.

Several researchers deal with various aspects of microgrid, such as the investigation of experimental microgrid systems installed in Asia, North America and Europe (EU) [11], microgrid (MG) protection and control schemes [12], and reactive power compensation technology in microgrid [13]. Furthermore they discussed the control method of inverter based microgrid [14], droop control technology [15], and the control strategy of microgrid frequency and voltage regulation [16]. They also studied the control strategy of distributed energy resource in microgrid [17], the planning, designing, modelling and architecture of the hybrid renewable microgrid [18], and the investigation of DC and AC microgrid [19]. The research also provides an overview of high-efficiency micro power generation systems based on steady-state control [20], microgrid uncertainty quantification techniques [21], and the use of network technology to conduct energy efficiency surveys in microgrid and buildings [22].

\section{MICROGRID (MG) ARCHITECTURE AND COMMUNICATION}

Microgrid is composed of different distributed energy resource, critical load and response load. Microgrid is connected to main utility grid through the point of common coupling (PCC) [23]. In the grid connected and island mode, every distributed energy resource is connected with power electronic interface (PEI) to achieve control, protection and metering goals. In grid connected mode, microgrid can use main utility grid to obtain the advantage of energy trading. However, if the main grid fails, microgrid will switch its operation to island mode to ensure the system reliability and stability. In this mode, it provides continuous power for critical loads through the efficient integrated operation of distributed energy resource, load shedding and demand response. Entire microgrid (MG) operations are coordinated and controlled by the Microgrid Central Controller (MGCC) and the Local Controller (LC) [24]. Effective coordination and management of distributed energy resource in microgrid can improve system performance as well as achieve sustainable development [25].

Because of the increased awareness of social and economic development and climate change, and need to reduce the emissions of greenhouse gas, microgrids are generally composed of renewable energy system (RES) and energysaving system that used local waste heat [26]. The optimization of these energy systems are achieved through microgrid energy management system that takes into account strategies for decision-making. These decisionmaking strategies consider improving efficiency of energy system, improving system reliability, reducing energy consumption, reducing system losses, reducing the operating costs of distributed energy resources, and reducing emissions of greenhouse gas (GHG) for sustainable development. In addition to working modes, microgird is also classified according to power supply type, power supply phase, supervisory control, and application.

The decentralized generation of distributed energy resources (DER) and the active integration of demand response require the communication infrastructures to share or exchange information with each other and optimize its operations [27], [28]. Then, an efficient and secure communication system are needed to carry out continuous, 
reliable, accurate and fast transfer of information between the sensor, Local Controller (LC) and Microgrid Central Controller without causing any interference or disconnection. However, the investment cost of this kind communication system may be high, depending on the number of repeaters that needed to improves the quality of the transmitted signal when covering a definite geographic region. Therefore, it is crucial to decrease installation costs while maintaining reliable operation by choosing the right communication technologies or system for long-distance and short-distance applications [29], [30].

\section{MICROGRID (MG) MODEL}

The development of new control strategies is needed for operating the microgrid (MG) within the scope of existing operating standards. According to the American National Standard Institute (ANSI) C84.1 standard, the utility company is require to maintain the voltage on the consumer service panel at 114.0 to $126.0 \mathrm{~V}( \pm 5.0 \%)$ based on rated secondary voltage of $120.0 \mathrm{~V}$. The Institute of Electrical and Electronics Engineers (IEEE) standard 1547 $\square 2 \square 2011$ recommend that when interconnecting distributed energy resources with electrical system, total time will be less than 0.15 second, when magnitude of voltage change exceed 5.0 percent and the magnitude of frequency change exceed 0.5 hertz [31].

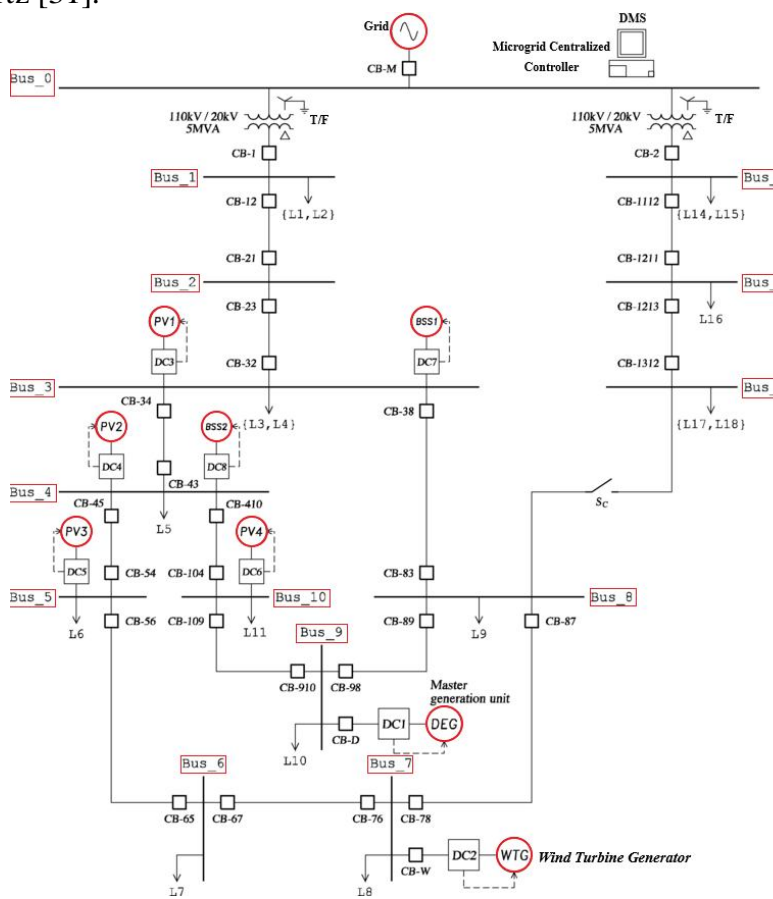

Figure 2:Microgrid (MG) Benchmark Model Configuration

Figure 2 shows the benchmark model configuration of microgrid (MG), which consists of two (2) feeders supplied by the distribution substation. The grid of distributed generation units are connected to left hand side feeder and includes four photovoltaic array units, one wind turbine generator, one diesel engine generator (DEG) and two battery storage system (BSS). The rated network voltage is 20.0 kilovolt that supplied by the 110.0 kilovolt $(\mathrm{T} / \mathrm{F})$ transformer. Network parameters, load and distributed generation unit (in pu) are summarized in Table 2 and Table 3.
Table 2: Load Parameters of the MG Model

\begin{tabular}{|l|c|c|c|c|}
\hline $\begin{array}{c}\text { Serial } \\
\text { No. }\end{array}$ & Load Type & $\begin{array}{c}\text { Load } \\
\text { No. }\end{array}$ & $\mathbf{P}_{\max }(\mathbf{p u})$ & $\mathbf{Q}_{\max }(\mathbf{p u})$ \\
\hline 1 & Residential & L1 & 0.14000 & 0.02900 \\
\hline 2 & Industrial & L2 & 0.05100 & 0.01100 \\
\hline 3 & Residential & L3 & 0.00286 & 0.00070 \\
\hline 4 & Industrial & L4 & 0.00234 & 0.00149 \\
\hline 5 & Residential & L5 & 0.00422 & 0.00106 \\
\hline 6 & Residential & L6 & 0.00730 & 0.00185 \\
\hline 7 & Residential & L7 & 0.00549 & 0.00139 \\
\hline 8 & Industrial & L8 & 0.00076 & 0.00049 \\
\hline 9 & Residential & L9 & 0.00578 & 0.00151 \\
\hline 10 & Industrial & L10 & 0.00584 & 0.00360 \\
\hline 11 & Industrial & L11 & 0.00069 & 0.00044 \\
\hline 12 & Residential & L12 & 0.00487 & 0.00119 \\
\hline 13 & Residential & L13 & 0.00330 & 0.00082 \\
\hline 14 & Residential & L14 & 0.14000 & 0.02900 \\
\hline 15 & Industrial & L15 & 0.05100 & 0.01710 \\
\hline 16 & Industrial & L16 & 0.00031 & 0.00021 \\
\hline 17 & Industrial & L17 & 0.00329 & 0.00019 \\
\hline 18 & Residential & L18 & 0.00211 & 0.00056 \\
\hline
\end{tabular}

Table 3: Parameters of Transmission Line

\begin{tabular}{c|c|c|c|c|c}
\hline \multicolumn{2}{|c|}{ Node } & $\begin{array}{c}\text { Resistance } \\
(\mathbf{R})\end{array}$ & $\begin{array}{c}\text { Reactance } \\
(\mathbf{X})\end{array}$ & $\begin{array}{c}\text { Capacitance } \\
(\mathbf{C})\end{array}$ & $\begin{array}{c}\text { Inductan } \\
\text { ce }(\mathbf{L})\end{array}$ \\
\hline From & To & $(\Omega / \mathrm{km})$ & $(\Omega / \mathrm{km})$ & $(\mathrm{nF} / \mathrm{km})$ & $(\mathrm{km})$ \\
\hline 0 & 1 & & & & \\
\hline 1 & 2 & 0.5780 & 0.3660 & 0157.870 & 2.8100 \\
\hline 2 & 3 & 0.1630 & 0.1120 & 6607.000 & 4.4100 \\
\hline 3 & 4 & 0.2610 & 0.1200 & 6479.000 & 0.6000 \\
\hline 4 & 5 & 0.3530 & 0.1280 & 4559.000 & 0.5500 \\
\hline 5 & 6 & 0.3350 & 0.1250 & 5487.000 & 1.5300 \\
\hline 6 & 7 & 0.2550 & 0.1290 & 3759.000 & 0.2300 \\
\hline 7 & 8 & 0.2930 & 0.1220 & 5599.000 & 1.6600 \\
\hline 8 & 9 & 0.3380 & 0.1290 & 4367.000 & 0.3100 \\
\hline 9 & 10 & 0.3980 & 0.1320 & 4831.000 & 0.7600 \\
\hline 10 & 11 & 0.3660 & 0.1320 & 4559.000 & 0.3200 \\
\hline 11 & 12 & 0.4220 & 0.1330 & 4959.000 & 0.4800 \\
\hline 12 & 13 & 0.3360 & 0.3570 & 0161.890 & 4.8800 \\
\hline 13 & 14 & 0.2010 & 0.1210 & 4783.000 & 2.9800 \\
\hline
\end{tabular}

Table 2 shows the maximum value of reactive power and active power that are taken into consideration in network parameters. Variable load curves were generated for loads L9, L7, L6, L2 and L1.

Main characteristics of distributed generation (DG) unit are following:

- Diesel Engine Generator: Diesel engine are used as prime mover of the synchronous generator. Frequency of the system is determined by diesel engine mechanical speed $(\omega \mathrm{m})$, and voltage magnitude set by the synchronous generator excitation current. Diesel engine generator (DEG) rated output power is $0.3124 \mathrm{pu}$ on a 5.0 MW Pbase.

- Wind Turbine Generator: The maximum output power of wind turbine generator is $0.20 \mathrm{pu}$.

- Photovoltaic Array: The key features of JA Solar 330.0 Watt photovoltaic modules (JAM60S10330/PR) are used. The PV1 array consist of 66.0 
string and each string have 5.0 series connected 330.0 watt JA Solar PV modules. In parallel, these strings are connected to provide $0.020 \mathrm{pu}$. PV2, PV3, and PV4 have power generation capacity of 0.020 , $4.0 \times 10-3$, and $5.0 \times 10-3$ pu respectively. The PCS (power conditioning system) of each photovoltaic array are composed of Voltage Source Converter (VSC) and boost converter.

- Battery Storage System: Lead acid battery is used in combination with a bidirectional AC/DC converter. The maximum output power of the (BSS) battery storage system number one (BSS1) is $0.020 \mathrm{pu}$, and the maximum output power of the (BSS) battery storage system number two (BSS2) is $0.015 \mathrm{pu}$. Charging power of each battery storage system is $0.010 \mathrm{pu}$.

Distributed energy resources does not allow system frequency adjustment. The distributed generation unit (except diesel engine generator) is therefore considered as a load node with negative power consumption in the power flow calculation. During grid connected operation, the main utility grid control frequency and voltage and during island operation the local MG control frequency and voltage.

\section{MATERIALS AND METHODS FOR ENERGY MANAGEMENT SYSTEM (EMS)}

\subsection{Non-linear Model Predictive Control (NMPC) Design}

These following equations have been developed for the design of the centralised non-linear model predictive control strategy.System state for island section of the distribution system (left feeder) in figure 2 is defined as

$$
\begin{aligned}
x=\left[\begin{array}{l}
x_{1} \\
x_{2}
\end{array}\right] & (1) \\
x_{1} & \in \mathbb{R}^{10} x_{1}=\left[V_{i}\right]^{T} \quad i=1,2,3,4, \ldots, 10 \\
x_{2} & \in \mathbb{R}^{10} x_{2}=\left[\delta_{i}\right]^{T} \quad i=1,2,3,4, \ldots, 10
\end{aligned}
$$

Where

- $V_{i}$ : voltage at the node of the bus i

- $\delta$ i: angle of the bus $\mathrm{i}$

In addition, the controller formula requires more variables and vectors, like the power at node $S_{i}=P_{i}+j Q_{i}$, the admittance matrix (Y) and the power produced by distributed generation units, $\mathrm{P}_{\mathrm{DGi}}$

$Y=\left[Y_{i, j}\right](2)$

$S=\left[\begin{array}{l}P_{\text {Load }} \\ Q_{\text {Load }}\end{array}\right] \quad \begin{array}{cc}P_{\text {Load }} \in \mathbb{R}^{10} P_{\text {Load }}=\left[P_{L i}\right]^{T} & i=1,2,3,4, \ldots, 10 \\ Q_{\text {Load }} \in \mathbb{R}^{10} Q_{\text {Load }}=\left[Q_{\text {Li }}\right]^{T} & i=1,2,3,4, \ldots, 10\end{array}$

Here

$$
P_{D G}=\left[P_{D G i}\right]^{T} \quad i=1,2,3,4, \ldots, 8(4)
$$

$$
\left\{\begin{array}{llr}
i=1 & \left.P_{D E} \text { (Diesel Engine Power }\right) \\
i=2 & \left.P_{W T} \text { (Wind Turbine Power }\right) \\
i=3 & P_{P V 1} & (\text { PV1 Array Power }) \\
i=4 & P_{P V 2} & (\text { PV2 Array Power }) \\
i=5 & P_{P V 3} & (\text { PV3 Array Power }) \\
i=6 & P_{P V 4} & (\text { PV4 Array Power }) \\
i=7 & P_{B S S 1} & \text { (BSS1 Power }) \\
i=8 & P_{B S S 2} & \text { (BSS2 Power })
\end{array}\right.
$$

$$
S_{i}=V_{i} \sum_{m=1}^{N}\left(Y_{i m} V_{i}\right)(6)
$$

Using the Newton Raphson power flow algorithm, equation number (6) is solved iteratively, taking into account the knowledge of PDGi and the current loads consumptions of each node of the power system. Within the prediction range of length N, PDE is estimated. The inclusion of reactive power consumed by wind turbine generator at the bus number 7 is an important modification of Equation (4), that is calculated as

$Q_{W T}=-\frac{V_{7}^{2}}{z_{p}}+\frac{-V_{7}^{2}+\sqrt{V_{7}^{4}-4 P_{7} z^{2}}}{2 z}(7)$

Where

- $\quad z=z_{1}+z_{2}$ and $z_{p}=\frac{z_{c} z_{m}}{z_{c}-z_{m}}$

- Negative sign (-) in Equation (7) represent reactive power consumption of wind turbine generator induction generator (WTG) from system

- $\quad$ zc: represents the reactance of the capacitor bank installed at terminal of induction generator.

- zm: represents excitation reactance

- $\mathrm{z}_{1}$ : represents stator reactance

- $\mathrm{z}_{2}$ : represents the rotor reactance

The control purposes of proposed strategy are following

- To monitor events of battery connection and disconnection.

- In order to reduce the low priority load if the load requirement is greater than the generating power. Through a predictive model, which can predict imbalances of potential load, this control operation predicts any harmful system operation.

- To retain the maximum change in voltage magnitude is \pm 5.0 percent.

The MG centralized controller (MGCC) implements the non-linear model predictive control algorithm. The control vector $(u)$ defined by equation (8) performs load management and battery connection and disconnection events. The control vector $(u)$ is computed by $\mathrm{MG}$ centralized controller in real time and transmitted to distributed controllers in MG. Table 4 lists the relationship between each control vector $(u)$ bit and its corresponding switching load controller, they are,

$u_{i}=1 \rightarrow L_{i}$ (When loads are connected $)$

$u_{i}=0 \rightarrow L_{i}$ (When loads are disconnected $)$

Table 4: Control Vector $(u)$ Correspondence with Loads and BSS

\begin{tabular}{|l|c|c|c|c|}
\hline $\begin{array}{c}\text { Serial } \\
\text { No. }\end{array}$ & Observations & Load & $\begin{array}{c}\text { Control } \\
\text { Signal } \\
(\boldsymbol{u})\end{array}$ & Priority \\
\hline 1 & Variable loads & $\begin{array}{l}\mathrm{L}_{1}= \\
\mathrm{L}_{1} \mathrm{U}_{2}\end{array}$ & $u_{1}$ & High \\
\hline 2 & Constant loads & $\mathrm{L}_{3} \mathrm{U} \mathrm{L}_{4}$ & $u_{2}$ & Low \\
\hline 3 & Constant load & $\mathrm{L}_{5}$ & $u_{3}$ & Low \\
\hline 4 & Variable load & $\mathrm{L}_{6}$ & $u_{4}$ & Low \\
\hline 5 & Variable load & $\mathrm{L}_{7}$ & $u_{5}$ & High \\
\hline 6 & Constant load & $\mathrm{L}_{8}$ & $u_{6}$ & High \\
\hline 7 & Constant load & $\mathrm{L}_{9}$ & $u_{7}$ & Low \\
\hline 8 & Constant load & $\mathrm{L}_{10}$ & $u_{8}$ & Low \\
\hline 9 & Constant load & $\mathrm{L}_{11}$ & $u_{9}$ & Low \\
\hline 10 & Charge mode & $\mathrm{BSS}_{1}$ & $u_{10}$ & - \\
\hline
\end{tabular}




\begin{tabular}{|l|c|c|c|c|}
\hline 11 & $\begin{array}{c}\text { Discharge } \\
\text { mode }\end{array}$ & $\mathrm{BSS}_{1}$ & $u_{11}$ & - \\
\hline 12 & Charge mode & $\mathrm{BSS}_{2}$ & $u_{12}$ & - \\
\hline 13 & $\begin{array}{c}\text { Discharge } \\
\text { mode }\end{array}$ & $\mathrm{BSS}_{2}$ & $u_{13}$ & - \\
\hline
\end{tabular}

$u=\left[u_{i}\right] \quad i=1,2,3,4, \ldots ., 13(8)$

$u_{i}$ : is binary signal

An important requirement in non-linear model predictive control algorithm (NMPC) design is that the model can be used to predict output variables. The non-linear model predictive control algorithm require a predicted value of power produced by the diesel engine generator (DEG) in order to optimally determine which load should be dropped. The trip command is sent from the microgird centralized controller to the appropriate load. Figure 3 shows the energy management system architecture.

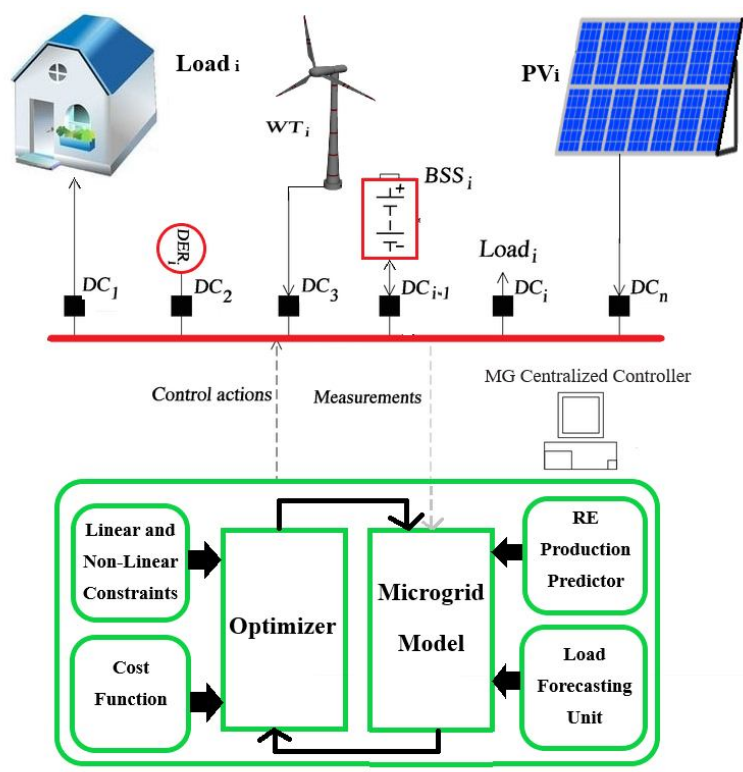

Figure 3:Non-linear Model Predictive Control Architecture for Centralized Load Shedding

To predict the system state of the microgrid (MG), and therefore predict the PDE within a particular prediction range $\mathrm{N}$, the Newton Raphson power flow algorithm are used. The disconnection and connection command of control vector $(u)$ with-in the Newton Raphson algorithm will be taken into consideration in order to find the best steady state function of MG. Before performing the Newton Raphson calculation, an initial $\left(Z_{k}\right)$ data set consisting of the battery state of charge, load demand and active power produced by each distributed energy resource is required. Within the prediction range, the data set $\left(\mathrm{Z}_{\mathrm{k}}\right)$ do not consider load changes. Considering this fact, two methods are tested against the initial iteration load value of Newton Raphson algorithm to predict the $\mathrm{P}_{\mathrm{DE}}$.

In the entire prediction range $\mathrm{N}$, the load measurement is consider as a constant.

Use load predictor based on ANN (artificial neural network). For that reason, for each variable load in the microgrid (MG), 20.0 load curves on different days of week are used as the training set to set up or for configuring the three layer artificial neural network.

Another PDE prediction method is the development of an adaptive neuro-fuzzy inference system (ANFIS) using an autoregressive external input model (ARX) for data based modeling. In the case of the artificial neural network training algorithm, the adaptive neuro-fuzzy inference (ANFIS) training set uses 20.0 different diesel engine generation curves on different days of the week. The modeling process do not imply Newton Raphson calculation, so calculation time of control algorithm is reduced.

\subsection{Non-linear Model Predictive Control Algorithm}

When the voltage (V) magnitude of MG should be kept or retained within the range of \pm 5.0 percent, the static voltage stability index is used to define the safe operating range of diesel engine generator. Consider the average power production value of diesel engine generator $(\mathrm{DEG})$ : $\mathrm{P}_{\mathrm{WT}}=$ $0.150, \Sigma \mathrm{P}_{\mathrm{PV} 1,2,3,4}=0.0490, \Sigma \mathrm{P}_{\mathrm{BSS} 1,2}=-0.020$ in charging mode, $\Sigma \mathrm{P}_{\mathrm{BSS} 1,2}=0.0350$ in discharge mode, and the voltage amplitude limit is $0.95 \leq \mid$ voltage $(\mathrm{V}) \mid \leq 1.05$, this is an optimization process in which the values of $\mathrm{Q}_{\mathrm{L}}, \mathrm{P}_{\mathrm{L}}$ and $|\mathrm{V}|$ are sweep to perform operations within the allowable range to obtain the safe operating margin of MG as follows.

$$
\begin{gathered}
|1-L| \\
P_{D E}+P_{W T}+\sum P_{P V 1,2,3,4}+\sum P_{B S S 1,2}=P_{L}+P_{\text {loss }} \quad(9) \\
L_{i+1}=4 \frac{\left(X_{e q} P_{L}-R_{e q} Q_{L}\right)^{2}+\left(X_{e q} Q_{L}+R_{e q} P_{L}\right) V_{i}^{2}}{V_{i}^{4}}<1 \\
0<P_{L}<P_{\max } \\
0<Q_{L}<Q_{\min } \\
0.95 \leq \mid \text { voltage }(V) \mid \leq 1.05(10) \\
\text { - } \quad X_{e q}: \text { is reactance of } \mathrm{MG} \\
\text { - } R_{e q}: \text { is resistance of } \mathrm{MG}
\end{gathered}
$$

Safe operating range of diesel engine is estimated through the optimization process that is

$P_{D E} \leq P_{D E}^{+}=0.20(11)$

Consequently, the cost function $\mathrm{J}$, which will be used in the optimization algorithm, will operate the microgrid (MG) master generation unit, diesel engine (DE), in a power generation range that ensures the stability of voltage. The cost function is defined as follows:

$J(x k)=\left(P_{D E}(x k)-r\right)^{2}(12)$

Where $P_{D E}(x k)$ is calculated by Newton Raphson algorithm or by the ARX adaptive neuro fuzzy inference system model. The (r) value is chosen to be less than $P_{D E}^{+}$.

Control vector is computed by non-linear model predictive control algorithm and this control vector is restricted to binary. This type of optimization problem is called a (MINLP) mixed integer non-linear programming problem. To solve this optimal control problem, the mixed integer non-linear programming package of TOMLAB for MATLAB is used. 


\section{RESULTS AND DISCUSSION}

\subsection{Simulation Results}

Transient response of voltage (V) magnitude of the microgrid (MG) node number 1 in the islanding operation is shown in figure 4. Near 4:00 in the morning, the diesel engine indicates a loss of efficiency in servo mechanism are used for the injection of fuel. Based on a combination of Kalman filter and parity space method, Fault Tolerant Model Prediction Control (FTMPC) is implemented on the basis of fault detection and diesel engine (DE) post-fault model estimation. A simple MPC (model predictive control) is also tested, which caused the MG to be unstable due to lack of adaptation to fault conditions.

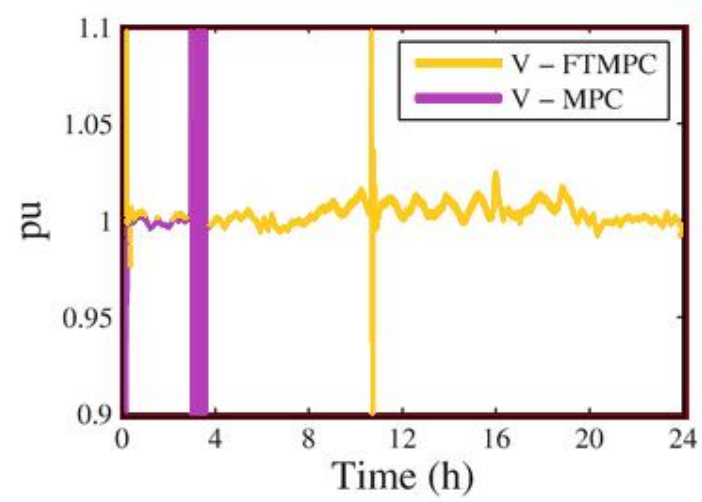

$4(a)$

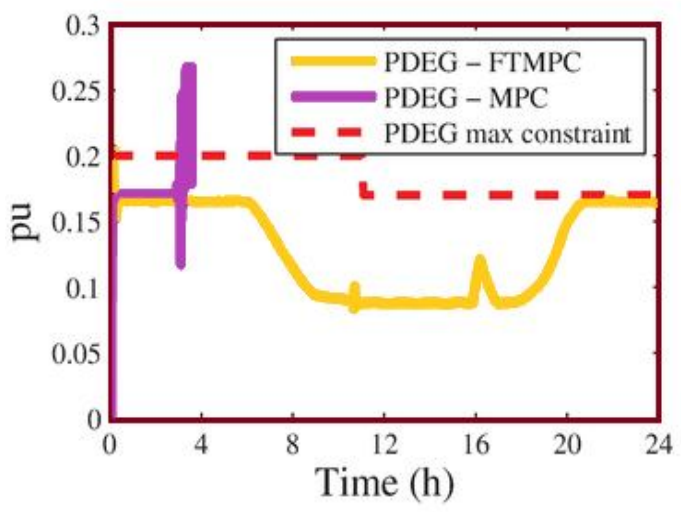

4(b)

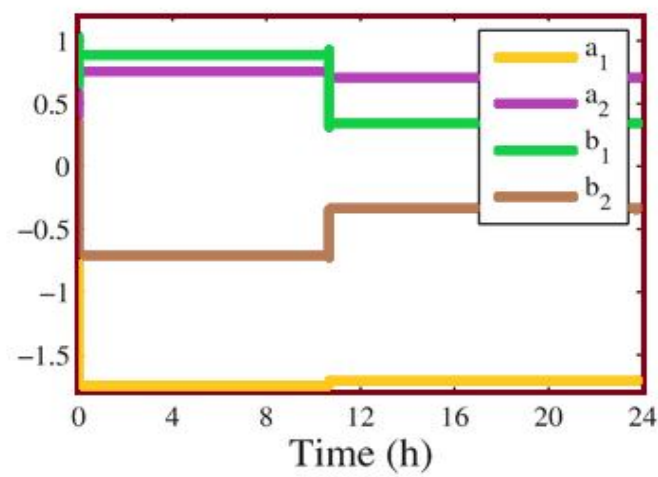

4(c)

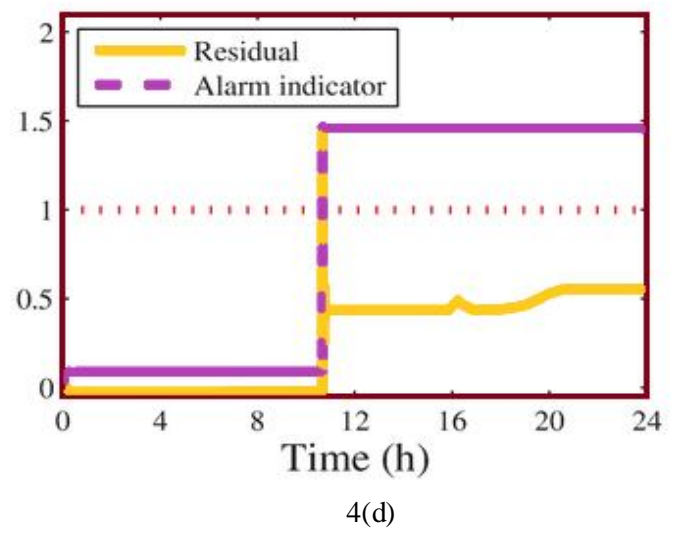

Figure 4: Simulation Result of Energy Management System Combining anNon-Linear Model Predictive Control (NMPC) AgorithmRunning at the MicrogridCentral Controller (MGCC), and Fault Tolerant Model Prediction Control Installed at the Diesel Engine Generator. (a) Voltage (V) Magnitude Response Comparisons between the Fault Tolerant Model Predictive Control and the Model Predictive Control System. (b) Power Output of Diesel Engine Generator Comparison. (c) Autoregressive External Input Model Parameter Adaptation of Diesel Engine Generator. (d) Residue Calculated by Fault Detection and Diagnosis Module.

Simulation also provide additional information about performance of non-linear model predictive control method by showing frequency and voltage of MG, and the load and battery switching based on non-linear model predictive control calculations. When MG operates in the islanding mode, the voltage magnitude remains within $\pm 5.0 \%$ at node 1 (weaker bus). In this operating mode, the voltage magnitude constraint/restriction will be violated when no control operation is performed. On other hand, it does not violate the constraints contained in the non-linear model predictive control algorithm. When capacity of the power generation is more than load $\left(\mathrm{P}_{\text {gen }}>\mathrm{P}_{\text {load }}\right)$ during off peak hours, batteries will be charged. When the power is insufficient due to peak consumption, the battery will supply power to the grid. The non-linear model predictive control (NMPC) algorithm includes load shedding and battery management functions, which can improve the overall performance of the microgrid by ensuring reliable, secure and safe operation.

Figure 5 show the operation of MG under similar condition as shown in Figures 4. The islanding event occurred at 12:00, and as predicted/expected, when the energy management system (EMS) takes decisions on battery management, the voltage magnitude variation will not exceed \pm 5.0 percent and low priorities load will be reduced. A similar situation are witnessed with frequency deviation from $1.0 \mathrm{pu}$, which remained within the acceptable or appropriate range of variation $(0.05 \%$ maximum). In contrast, simulation of the MG operation without energy management system (EMS) show unsafe or unsecure system behavior that violates $|\Delta \mathrm{V}|< \pm 5.0$ percent of operating constraints, and also show greater frequency changes, as shown in Figure 5.

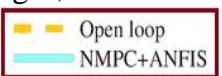




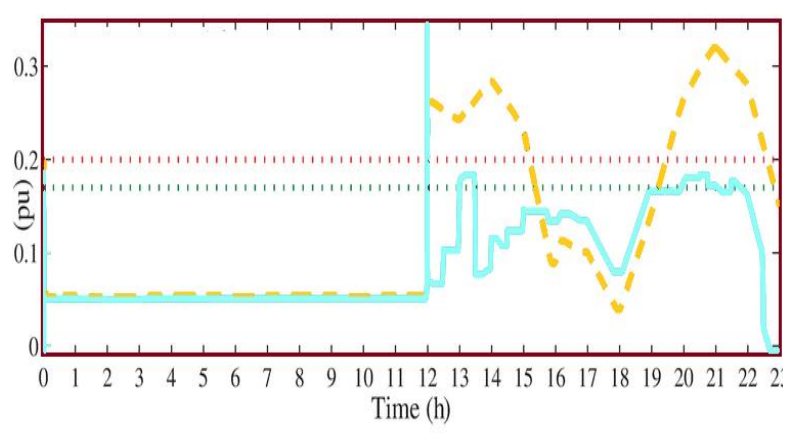

$5(\mathrm{a})$

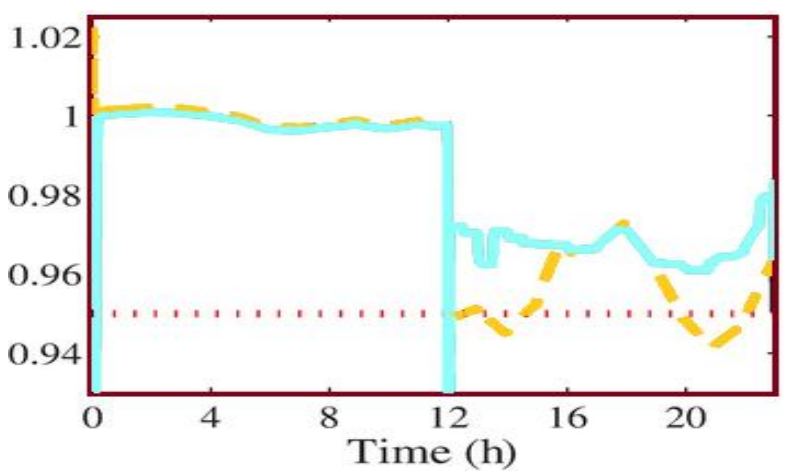

5 (b)

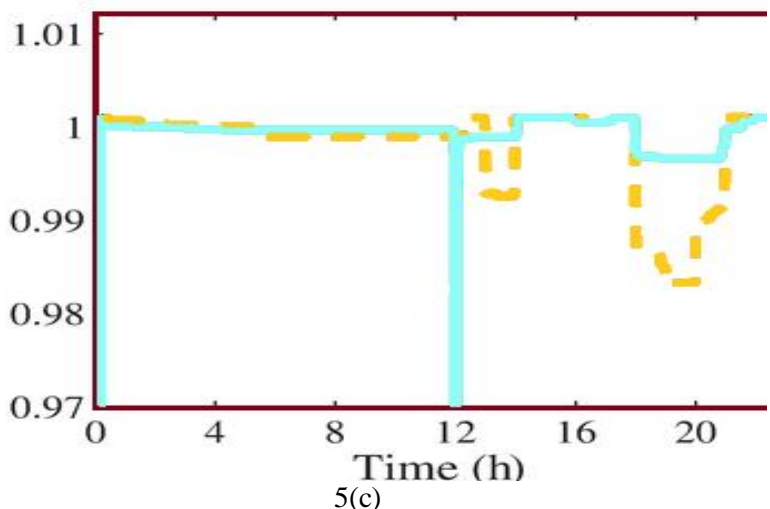

Figure 5: (a) PDE when Non-Linear Model Predictive Control Strategy of Load Shedding is used (Islanding Event Occurred at 12:00). (b) Variation of Voltage Magnitude. (c) Variation of Frequency Magnitude.

\subsection{Experimental Results}

A medium scale system have been installed in order to test our energy management system. The microgrid (MG) consists of a $33.0 \mathrm{kV}$ utility grid power, $260.0 \mathrm{~kW}$ photovoltaic power, $100.0 \mathrm{~kW}$ wind power, 100.0 KVA diesel engine (DE) and battery storage system includes the batteries of capacity (200.0 Ah). All energy resources (wind, solar etc) are simulated taking into account the cumulative dynamic load in residential and industrial premises. Wapda City, Jhimpir, Sindh, is taken as a case study. Meteorological Department of Pakistan tracks or record irradiance $(\mathrm{W} / \mathrm{m} 2)$, wind speed $(\mathrm{m} / \mathrm{s})$ and ambient temperature $\left({ }^{\circ} \mathrm{C}\right)$.
In the microgrid (MG), there are two types of loads: industrial and residential load. industrial and residential loads are connected to the AC bus. All renewable energy resources, diesel engine (DE), storage system and the utility grid supply power to the total load (PI+PR) through the AC bus. Figure 6 demonstrates the active and reactive power of $\mathrm{AC}$ bus. To ensure the energy balance between generation and load, the non-linear model predictive control (NMPC) algorithm properly manages the grid inverter by tracking the active and reactive power reference trajectories. Steady state error with the non-linear model predictive control (NMPC) algorithm is $1.0 \mathrm{~kW}$ and the undershoot is just 2.0 percent.
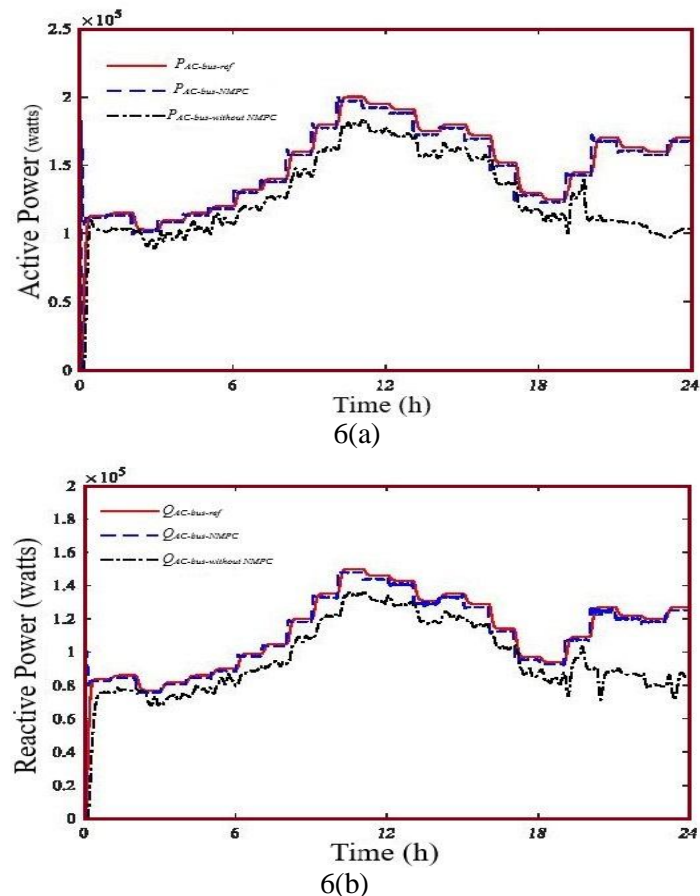

Figure 6: (a) AC Bus Active Power (watts) (b) AC Bus Reactive Power (watts)

Bidirectional power flow between the microgrid (MG) and the electrical system is the responsibility of the microgrid's DC/AC converter. Figure 7 shows the active and reactive power of the DC/AC converter for microgrid. The microgrid takes 50.0 kilowatt of power from the utility grid for $0-2 \mathrm{~h}$. That power of 50.0 kilowatt are used to charge the battery storage system. The MG uses 70.0 kilowatt of power from the grid during the $4-5 \mathrm{~h}$ time interval. The microgrid (MG) supplies the power to the electrical system during 11-12 $\mathrm{h}, 14-15 \mathrm{~h}$ and 16-17 $\mathrm{h}$ time intervals. The microgrid (MG) supplies 30.0 kilowatt of power to the electrical system during 18-22 h time intervals. Non-linear model predictive control (NMPC) algorithm and advanced metering infrastructure (AMI) closely monitors the active and reactive power of the microgrid (MG).

To Track the reference trajectories of microgrid (MG) active and reactive power, the non-linear model predictive control (NMPC) algorithm and advanced metering infrastructure (AMI) system adequately controls the DC/AC inverter. As a result less steady state errors and fewer oscillations in microgrid (MG) with energy management system (EMS) as compared to traditional or 
conventional microgrid (MG) without energy management system (EMS) shown in Figure 7.
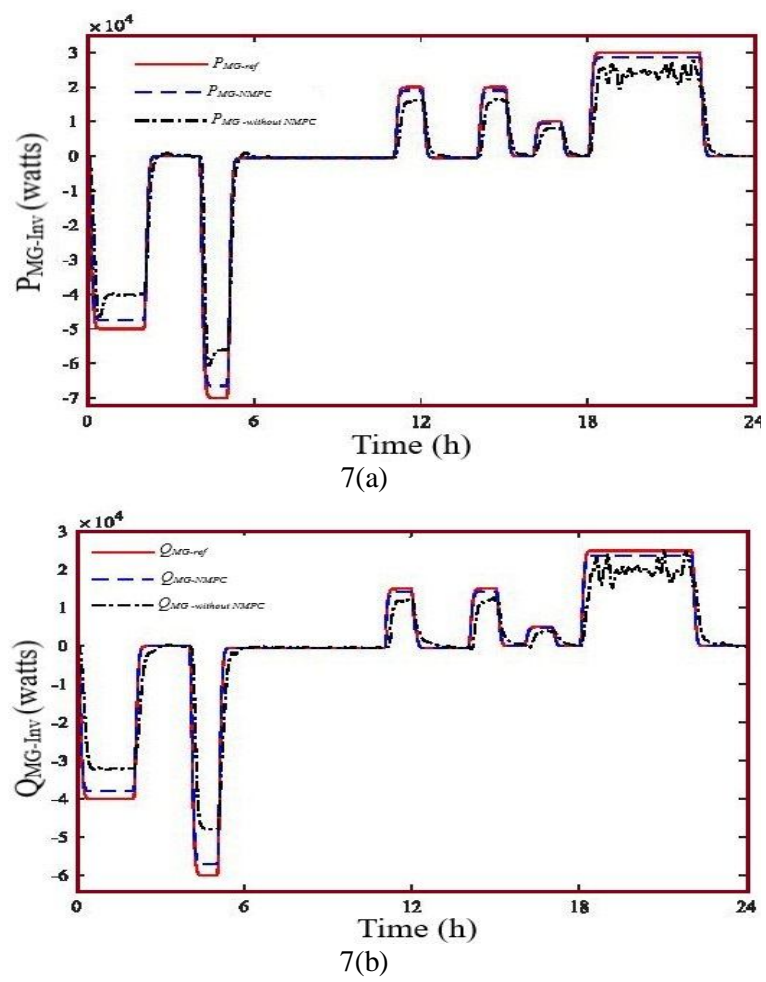

Figure 7: (a) MG converter active power (watts) (b) A MG converter bus reactive power (watts)

Microgrid (MG) have a battery storage system. These battery storage system serve as either load or source of power. Battery storage system have own buck-boost converter. Buck mode are used to charge the battery storage system, while the battery storage system is discharged by using the Boost mode. Non-linear model predictive control (NMPC) algorithm and advanced metering infrastructure (AMI) control buck-boost converter. Each buck-boost converter delivers or extracts the power to battery storage system based or depend on the reference power.

\section{CONCLUSION}

This paper analyzes a predictive control scheme that can prevent the imbalance between load demands and power generation capacity installed in the island microgrid (MG). Non-linear model predictive control (NMPC) calculates the necessary load shedding and energy management of the battery storage system in the microgrid (MG) within the optimization framework. Then, an optimum control problem are established in which all microgrid (MG) operating conditions are integrated, i.e. load priorities for disconnection and battery charging and discharging cycles. A comparisons of the some simulation result of $\mathrm{MG}$ (microgrid) operating with and without the Microgrid Centralized Controller (MGCC) show that when the microgrid (MG) operate in island mode, the reliability of microgrid (MG) is improved because the simulation result showed the ability/capacity of the control strategy that maintain frequency and voltage of the microgrid (MG) within safe and secure limits, as well as a correct balance of load demands and power generation.

\section{ACKNOWLEDGEMENTS}

The authors gladly acknowledge the continued support and inspiration from our beloved parents. Also we extend the vote of thanks to the Department of Electrical Engineering, GC University Faisalabad and Department of Automotive Engineering for Sustainable Mobility, University of Orleans for providing a learning environment.

\section{DATA AVAILABILITY STATEMENT}

The data that support the findings of this study are available from the corresponding author upon reasonable request.

\section{REFERENCES}

1.J. Wu, J. Yan, H.Jia,N. Hatziargyriou, N. Djilali andH. Sun. Integrated energy systems. Applied Energy, vol. 167, pp. 155-157, 2016. doi: 10.1016/j.apenergy.2016.02.075

2.J. Keirstead, M. Jennings and A. Sivakumar.A review of urban energy system models: approaches, challenges and opportunities.Renewable and Sustainable Energy Reviews,vol. 16(6), pp. 3847-3866, 2012. doi: 10.1016/j.rser.2012.02.047

3.H. Hu, N. Xie, D. Fang and X. Zhang.The role of renewable energy consumption and commercial services trade in carbon dioxide reduction: evidence from 25 developing countries.Applied Energy,vol. 211, pp. 1229-1244, 2018. doi: 10.1016/j.apenergy.2017.12.019

4.S. Parhizi,H. Lotfi, A. Khodaei and S.Bahramirad. State of the art in research on microgrids: A review. IEEE Access, vol. 3, pp. 890-925, 2015. doi: 10.1109/ACCESS.2015.2443119

5.S. Bacha, D. Picault, B. Burger, I. Etxeberria-OtaduiandJ. Martins.Photovoltaics in microgrids: an overview of grid integration and energy management aspects.IEEE Industrial Electronics Magazine, vol. 9(1), pp. 33-46, 2015. doi: 10.1109/MIE.2014.2366499

6.N. Hatziargyriou, H. Asano, R. Iravani and C. Marnay.Microgrids. IEEE Power and Energy Magazine, vol. 5(4), pp. 78-94, 2007. doi: 10.1109/MPAE.2007.376583

7. DOE. Summary report. DOE microgrid workshop, Chicago, Illinois, 2012.

8.R. Lasseter, A. Akhil, C. Marnay, J. Stevens, J.Dagle and R. Guttromson et al.The certs microgrid concept, white paper on integration of distributed energy resources. California Energy Commission, Office of Power Technologies-US Department of Energy, LBNL-50829, 2002. http://certs.lbl.gov.

9.R. Secretariat.Renewables 2017 global status report. ren21, Paris, Tech. Rep. 2017.

10. N. Hatziargyriou, et al. Microgrids: architectures and control. John Wiley \& Sons, 2014.

11.N. W. Lidula and A. D. Rajapakse. Microgrids research: a review of experimental microgrids and test systems. Renewable and Sustainable Energy Reviews, vol. 15(1), pp. 186-202, 2011.

12.S.A Gopalan, V. Sreeram and H. H. Iu. A review of coordination strategies and protection schemes for microgrids.Renewable and Sustainable Energy 
Reviews, vol. 32, pp. 222-228, 2014. doi: 10.1016/j.rser.2014.01.037

13.M. Gayatri, A. M. Parimi and A. P. Kumar. A review of reactive power compensation techniques in microgrids: A Survey Paper.Renewable and Sustainable Energy Reviews, vol. 81(1), pp. 1030-1036, 2018.

14.M. H. Andishgar, E. Gholipour and R. A. Hooshm and. An overview of control approaches of inverter-based microgrids in islanding mode of operation. Renewable and Sustainable Energy Reviews, vol. 80, pp. 1043-1060, 2017. doi: 10.1016/j.rser.2017.05.267

15.U. B. Tayab, M. A. B. Roslan, L. J. Hwaiand M. Kashif. A review of droop control techniques for microgrid.Renewable and Sustainable Energy Reviews, vol. 76, pp. 717-727, 2017. doi: 10.1016/j.rser.2017.03.028

16.S. M. Malik, X. Ai, Y. Sun,C.Zhengqi, and Z.Shupeng. Voltage and frequency control strategies of hybrid AC/DC microgrid: A review.IET Generation, Transmission \& Distribution, vol. 11(2), pp. 303-313, 2017. doi: 10.1049/iet-gtd.2016.0791

17.B. M. Eid, N. Abd-Rahim, J. Selvaraj and A. H.ElKhateb. Control methods and objectives for electronically coupled distributed energy resources in microgrids: A review.IEEE systems journal, vol. 10(2), pp. 446-458, 2014. doi: 10.1109/JSYST.2013.2296075

18.S. M. Dawoud, X. Lin and M. I. Okba. Hybrid renewable microgrid optimization techniques: A review. Renewable and Sustainable Energy Reviews, vol. 82, pp. 2039-2052, 2018. doi: 10.1016/j.rser.2017.08.007

19.J. J. Justo, F. Mwasilu, J. Lee and J. W. Jung. ACmicrogrids versus DC-microgrids with distributed energy resources: A review. Renewable and Sustainable Energy Reviews, vol. 24, pp. 387-405, 2013. doi: 10.1016/j.rser.2013.03.067

20. F. F. Yanine and E. E. Sauma EE. Review of grid-tie micro-generation systems without energy storage: Towards a new approach to sustainable hybrid energy systems linked to energy efficiency.Renewable and Sustainable Energy Reviews, vol. 26, pp. 60-95, 2013. doi: 10.1016/j.rser.2013.05.002

21.K. P. Kumar and B. Saravanan. Recent techniques to model uncertainties in power generation from renewable energy sources and loads in microgrids-a review. Renewable and Sustainable Energy Reviews, vol. 71, pp. 348-358, 2017. doi: 10.1016/j.rser.2016.12.063

22.J. Pan, R. Jain andS. Paul. A survey of energy efficiency in buildings and microgrids using networking technologies. IEEE Communications Surveys \& Tutorials, vol. 16(3), pp. 1709-1731, 2014. doi: 10.1109/SURV.2014.060914.00089

23.G. Davis. Integration of distributed energy resources the certs microgrid concept. California Energy Commission, 2003

24.Y. Li andF. Nejabatkhah. Overview of control, integration and energy management of microgrids.Journal of Modern Power Systems and Clean Energyvol. 3(2), pp. 212-222, 2014. doi: 10.1007/s40565-014-0063-1

25.N. Hatziargyriou, N. Jenkins, G. Strbac, J. P. Lopes, J. Ruela and Engler A, et al. Microgrids-large scale integration of microgeneration to low voltage grids.Conseil International des GrandsRéseauxElectriques, Paris, France, 2006. https://hal-mines-paristech.archives-ouvertes. fr/hal00526633

26.M. Li, X. Zhang,G, Li and C. Jiang. A feasibility study of microgrids for reducing energy use and GHG emissions in an industrial application.Applied Energy, vol. 176, pp. 138-148, 2016. doi: 10.1016/j.apenergy.2016.05.070

27.V. C. Gungor, D. Sahin, T. Kocak, S. Ergut, C. Buccella and C. Cecatiet al. Smart grid technologies: Communication technologies and standards. IEEE TransIndustrInfor IEEE transactions on Industrial informatics, vo. 7(4), pp. 529-539, 2011. doi:10.1109/TII.2011.2166794.

28.B. Wang, M. Sechilariu and F. Locment. Intelligent DC microgrid with smart grid communications: Control strategy consideration and design.IEEE Transactions on Smart Grid,vol. 3(4), pp. 2148-2156, 2012. doi: 10.1109/TSG.2012.2217764

29.A. Usman and S. H. Shami. Evolution of communication technologies for smart grid applications. Renewable and Sustainable Energy Reviews, vol. 19, pp. 191-199, 2013. doi: 10.1016/j.rser.2012.11.002

30.F. Gómez-Cuba, R. Asorey-Cacheda and F. J. Gonzalez-Castano. Smart grid last-mile communications model and its application to the study of leased broadband wired-access.IEEE Transactions on Smart Grid, vol. 4(1), pp. 5-12. doi: 10.1109/TSG.2012.2223765

31IEEE Standards Association. IEEE std 1547.4-2011, IEEE guide for design, operation, and integration of distributed resource island systems with electric power systems.New York IEEE,pp. 1-54, 2011 .doi: 10.1109/IEEESTD.2011.5960751. 